\title{
Genetic Variation Associated with Tamoxifen Effectiveness in American Indians and Alaska Natives with Breast Cancer
}

Burhan A. Khan

Renee Robinson

Alison E. Fohner

LeeAnna I. Muzquiz

Brian D. Schilling

Julie A. Beans

Matthew J. Olnes

Laura Trawicki

Holly Frydenlund

Cindi Laukes

Patrick Beatty

Brian Phillips

Deborah Nickerson

Kevin Howlett

Denise A. Dillard

Timothy A. Thornton

Kenneth E. Thummel

Erica L. Woodahl

\section{Video Byte}

Keywords: tamoxifen, CYP2D6, breast cancer, American Indian, Alaska Native, metabolism, endoxifen, Salish, Kootenai, medication, CSKT Tribal Health, women

Posted Date: February 19th, 2020

DOI: https://doi.org/10.21203/rs.2.24080/v1

License: (c) (i) This work is licensed under a Creative Commons Attribution 4.0 International License. Read Full License 


\section{Abstract}

Research has identified remarkably effective treatments for breast cancer But translation of these results to all patients requires pharmacogenetic research using diverse patient populations Although tamoxifen has been used to reduce the risk of breast cancer recurrence for the past 40 years Little is known about how well the drug works in American Indian and Alaska Native (AIAN) people A recent study focused on genetic variants of the cytochrome P450 gene CYP2D6, which is critical for tamoxifen activation Looking at AIAN participants in Alaska and Montana they identified common CYP2D6 variants in these populations that may affect tamoxifen metabolism Patients with these variants may not respond well to tamoxifen treatment and may benefit from alternative therapies This study highlights the key role of CYP2D6-mediated metabolism in tamoxifen response and suggests that considering genetic variation in diverse populations can help to improve the efficacy of breast cancer treatment We thank women from the Confederated Salish and Kootenai Tribes who participated in the research and the CSKT Tribal Council and CSKT Tribal Health who approved it 